\title{
Estudos preliminares da interesterificação do óleo de soja com acetato de metila catalisada por materiais lamelares
}

\author{
Preliminary studies on the interesterification \\ of soybean oil with methyl acetate catalyed \\ by layered materials"
}

Aligia Arrubia Useda ${ }^{1}$, Fernando Wypych ${ }^{1}$, Claudiney Soares Cordeiro ${ }^{1}$

\author{
${ }^{1}$ Universidade Federal do Paraná, Centro de Pesquisa em Química Aplicada (CEPESQ), Departamento de Química, CP \\ 19081, CEP: 81531-980, Curitiba, PR, Brasil. \\ e-mail: ali.useda@gmail.com,wypych@ufpr.br, claudiney@quimica.ufpr.br
}

\begin{abstract}
RESUMO
A substituição parcial do óleo diesel pelo biodiesel tem contribuído para o aumento da disponibilidade de glicerina no mercado mundial. Cerca de $10 \mathrm{~m}^{3}$ de glicerina são obtidos para cada $100 \mathrm{~m}^{3}$ de triacilglicerídeos (principal componente de óleos vegetais e gorduras animais) processados na principal rota tecnológica para produção do biodiesel, a transesterificação alcalina em meio homogêneo. Naturalmente, a glicerina obtida como coproduto no processo precisa ser aproveitada em processos complementares. Isso usualmente é possível após a glicerina passar por vários processos de purificação. Com a intenção de evitar tais processos complementes para aproveitamento da glicerina, estamos propondo a síntese do biodiesel por interesterificação do óleo de soja com acetato de metila, uma rota tecnológica que possibilita a obtenção da glicerina na forma de triacetina, ou seja, já quimicamente modificada. Os catalisadores utilizados no processo foram o hidróxido duplo lamelar (HDL) $\mathrm{Zn}_{2} \mathrm{Al} / \mathrm{NO}_{3}$ e o estearato de zinco comercial (EZ), um carboxilato lamelar. Ambos estes materiais lamelares ainda não haviam sido testados como catalisadores em reações de interesterificação. Foram obtidas conversões em ésteres

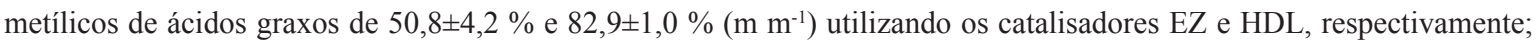
quando as reações foram conduzidas utilizando $5 \%$ de catalisador $\left(\mathrm{m} \mathrm{m}^{-1}\right)$, por $10 \mathrm{~h}$ de reação e razão molar acetato de metila: óleo de soja de 24:1.
\end{abstract}

Palavras-chave: biodiesel, glicerina, triacetina, interesterificação, materiais lamelares.

\begin{abstract}
The partial replacement of diesel oil with biodiesel has contributed to the increased availability of glycerin on the world market. About $10 \mathrm{~m}^{3}$ of glycerol is obtained for every $100 \mathrm{~m}^{3}$ of triacylglycerides (main component of vegetable oils and animal fats) processed in the main technological route for biodiesel production, the alkaline transesterification in homogeneous medium. Of course, the glycerin obtained as a coproduct in the process needs to be harnessed in complementary processes. This is usually possible after the glycerin undergoes several purification processes. With the intention of avoiding such complementary processes, we are proposing the synthesis of biodiesel by interesterification of soybean oil with methyl acetate, a technological route that makes it possible to obtain glycerol in the form of triacetin, that is, already chemically modified. The catalysts used in the process were the layered double hydroxide (HDL) $\mathrm{Zn} 2 \mathrm{Al} / \mathrm{NO}_{3}$ and the commercial zinc stearate (EZ), a layered carboxylate. Both these layered materials had not yet been tested as catalysts in interesterification reactions. Conversions were obtained in fatty acid methyl esters of $50.8 \pm 4.2 \%$ and $82.9 \pm 1.0 \%\left(\mathrm{~m} \mathrm{~m}^{-1}\right)$ using the EZ and HDL catalysts, respectively; when reactions were conducted using $5 \%$ catalyst $\left(\mathrm{m} \mathrm{m}^{-1}\right)$, for $10 \mathrm{~h}$ reaction and molar ratio methyl acetate: soybean oil of 24:1.
\end{abstract}

Keywords: biodiesel, glycerin, triacetin, interesterification, layered materials. 


\section{INTRODUÇÃO}

O uso de combustíveis fósseis tem contribuído para o decréscimo da qualidade do ar nos grandes centros urbanos, bem como para o aumento da temperatura global devido à emissão de gases do efeito estufa. A substituição parcial do óleo diesel pelo biodiesel é uma das medidas que tem sido amplamente adotadas para minimizar estes problemas. O biodiesel pode ser obtido a partir de várias rotas tecnológicas, porém, a transesterificação de triacilglicerídeos em meio acalino homogêneo ainda é a mais utilizada (Figura 1). Neste método, os íons alcóxidos, produzidos in situ ou adicionados diretamente no meio de reação, são utilizados como nucleófilos. O ataque nucleofílico ao carbono carbonílico do triacilglicerídeo leva a formação de um intermediário tetraédrico instável. O colapso deste intermediário no sentido direto leva a formação de uma molécula de éster de ácido graxo (biodiesel) e a base conjugada de um diacilglicerídeo que, após protonada, produz o próprio diacilglicerídeo. Após mais dois ciclos de reação têm-se a formação de mais duas moléculas de ésteres de ácidos graxos e uma molécula de glicerol [1-3].

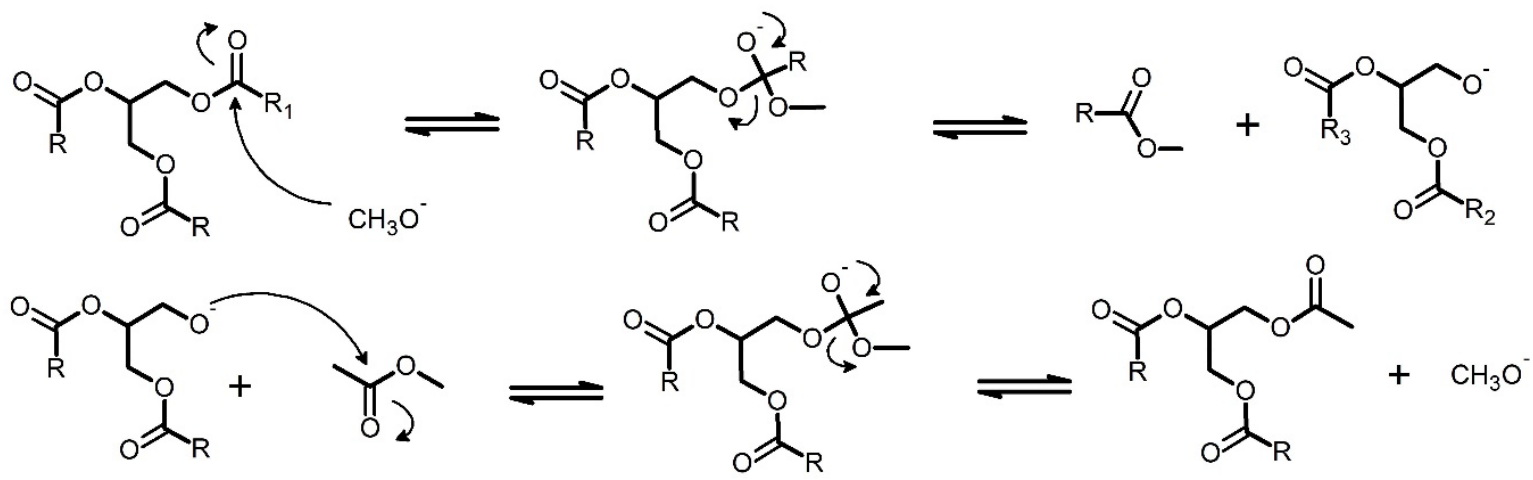

Figura 1: Esquema mostrando parte do mecanismo de transesterificação de triacilglicerídeos em que o metóxido é utilizado como nucleófilo. R representa grupamentos alquila.

A alcoólise de triacilglicerídeos em meio alcalino homogêneo possibilita a obtenção rendimentos elevados em ésteres de ácidos graxos quando executada adequadamente, porém, há várias exigências de processo que precisam ser consideradas. A matéria-prima deve possuir baixa acidez de Brönsted para minimizar os problemas inerentes a reações de saponificação, que, além de diminuir o rendimento do processo, dificulta as etapas posteriores de purificação devido ao favorecimento da formação de emulsões. A presença de água na matéria-prima também é indesejável pois a reação de hidrólise concorre com a reação de transesterificação. Em resumo, o processo exige o uso de matérias-primas que usualmente possuem alto valor agregado, como o óleo de soja que é amplamente utilizado para produção de biodiesel no Brasil. Outra questão a ser considerada é o baixo grau de pureza glicerina obtida nesse processo que dificulta o seu aproveitamento em processos complementares [1, 4-5].

Entre as alternativas disponíveis ao processo de produção tradicional pode-se destacar o uso de sólidos ácidos de Lewis como catalisadores heterogêneos. Embora esses catalisadores usualmente exijam o uso de condições de reação mais enérgicas, muitas vantagens podem ser atribuídas a eles. Em primeiro lugar pode-se destacar que em geral estes catalisadores podem ser facilmente reutilizados. No processo tradicional a recuperação do catalisador é de difícil execução. Além disso, é possível o uso de matérias-primas com elevado índice de acidez (que usualmente são de menor valor agregado) já que estes sólidos ácidos são capazes de catalisar reações de esterificação e transesterificação. No processo em meio heterogêneo é obtida ainda uma fase rica em ésteres de ácidos graxos de elevada pureza e; naturalmente, a fase glicérica também é mais pura [3, 6-8].

Embora a transesterificação em meio heterogêneo apresente muitas vantagens em relação ao processo tradicional ainda se faz necessário o uso de processos complementares para beneficiamento do glicerol. Neste trabalho estamos propondo o uso de catalisadores heterogêneos para síntese do biodiesel, porém, utilizando uma rota tecnológica denominada interesterificação (Figura 2). Neste processo, um mol de triacilglicerídeo reage com três mols de um éster de cadeia curta, como o acetato de metila por exemplo, levando a formação de três mols de ésteres de ácidos graxos e um mol de triacetina, ou seja, a glicerina já quimicamente modificada [9-11]. Cabe ressaltar que, assim como na reação de transesterificação em meio heterogêneo, na reação de interesterificação em meio heterogêneo os produtos de reação são obtidos com maior grau de pureza em relação a processos em meio homogêneo. 


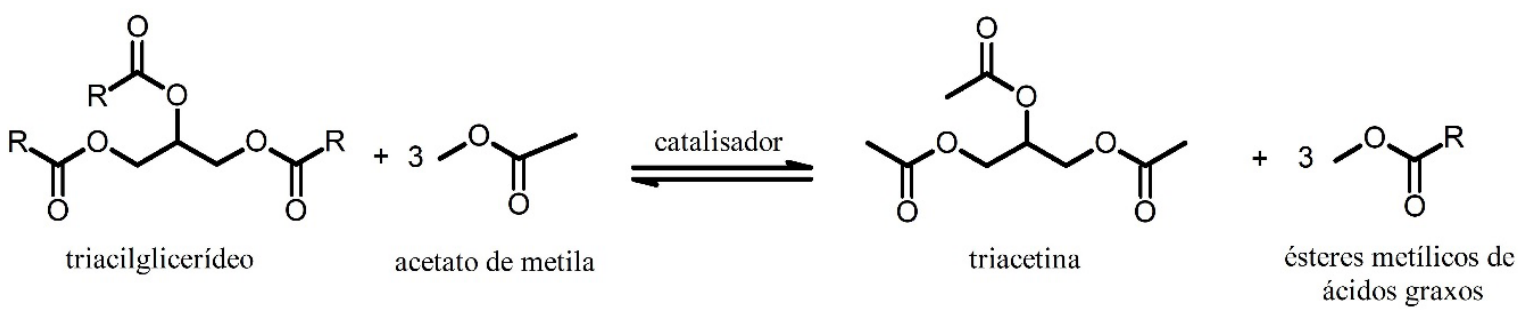

Figura 2: Esquema de uma reação de interesterificação de triacilglicerídeos com acetato de metila. R representa grupamentos alquila.

A triacetina obtida como coproduto no processo de interesterificação é um líquido oleoso utilizado em vários seguimentos industriais. Serve como plastificante do acetato de celulose contido nos filtros para cigarros, como acelerador de cura em resinas de autocurado da indústria da fundição, como agente fixador em perfumaria, como solvente para especialidades químicas, como fungicida, na manufatura de cosméticos e também para o recobrimento de comprimidos de aplicação farmacêutica. É utilizado ainda para a remoção do gás carbônico do gás natural e também para melhorar algumas propriedades de combustíveis do diesel e biodiesel, tais como o ponto de fluidez e o perfil de emissão de materiais particulados [12]. Algumas propriedades combustíveis do biodiesel, como o ponto de névoa e o ponto de orvalho, são melhoraras com a adição de triacetina [13-14].

As reações de esterificação, transesterificação e interesterificação são classificadas como reações de substituição nucleofílica acílica. Em ambas essas reações, o carbono carbonílico é um eletrófilo relativamente fraco que é colocado para reagir com um álcool de cadeia curta (usualmente metanol ou etanol) em reações de (trans)esterificação, ou com um éster como o acetato de metila em reações de interesterificação. Em ambos os casos o nucleófilo da reação também é relativamente fraco. Em geral, os sólidos ácidos de Lewis coordenam com o oxigênio da carbonila de ácidos carboxílicos e seus derivados. Como resultado, tem-se o aumento da eletrofilicidade deste carbono carbonílico, facilitando assim o ataque nucleofílico mesmo com o uso de nucleofílicos relativamente fracos (Figura 3) [1, 6].

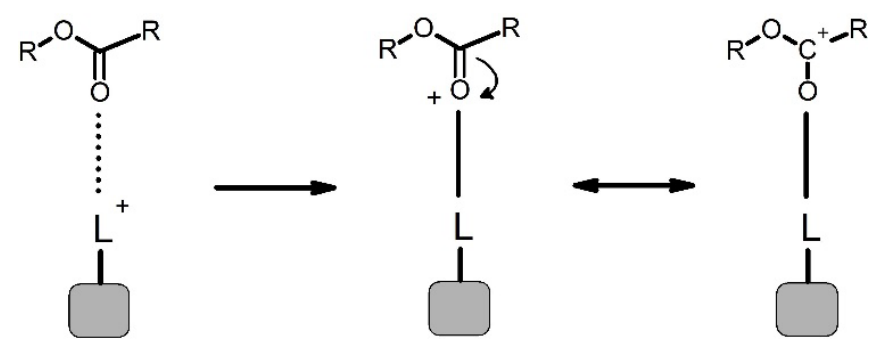

Figura 3: Esquema geral mostrando a interação de um sítio ácido de Lewis com a carbonila de um derivado de ácido carboxílico. $\mathrm{R}$ representa grupamentos alquila.

Os sólidos utilizados como catalisadores neste trabalho para a interesterificação do óleo de soja refinado com acetato de metila correspondem ao hidróxido duplo lamelar $\mathrm{Zn} \mathrm{Al}_{2} / \mathrm{NO}_{3}$ e o estearato de zinco comercial, este último um carboxilato lamelar. Estes materiais possuem atividade catalítica comprovada em processos de transesterificação e esterificação [15-20]. Porém, considerando que os autores não encontraram trabalhos análogos na literatura, pode-se dizer que é a primeira vez que estes sólidos são testados como catalisadores em reações de interesterificação para produção de biodiesel e triacetina.

\section{MATERIAIS E MÉTODOS}

\subsection{Materiais}

O óleo de palma e o estearato de zinco comercial utilizados neste trabalho foram gentilmente cedidos pela Agropalma (Belém, PA) e pela SIM Estearina Indústria e Comércio (Curitiba, PR), respectivamente. Os demais reagentes foram utilizados em grau analítico. 


\subsection{Métodos}

O índice de acidez do óleo de soja foi determinado utilizando-se a norma AOCS Ca 5a-40 (American Oil Chemists'Society), que consiste na titulação de uma solução contendo aproximadamente $1 \mathrm{~g}$ de amostra com uma solução padronizada de hidróxido de sódio $0,1 \mathrm{~mol} \mathrm{~L}^{-1}$.

A massa molar média do óleo de soja foi determinada por cálculo estequiométrico a partir do índice de saponificação (norma AOCS Cd-325), que corresponde ao número de miligramas de hidróxido de potássio necessário para saponificar $1 \mathrm{~g}$ de amostra. Neste método, $2 \mathrm{~g}$ de amostra são dissolvidos em $50 \mathrm{~mL}$ de solução alcoólica de hidróxido de potássio $0,5 \mathrm{~mol}$ $\mathrm{L}^{-1}$ e aquecidos sob refluxo por $30 \mathrm{~min}$. A quantidade de base remanescente é determinada por titulação com uma solução padronizada $0,5 \mathrm{~mol} \mathrm{~L}^{-1}$ de ácido clorídrico.

O hidróxido duplo lamelar (HDL) $\mathrm{Zn}_{2} \mathrm{Al} / \mathrm{NO}_{3}$ foi sintetizado utilizando-se o método da coprecipitação em meio alcalino. Foi preparada uma solução aquosa contendo nitrato de zinco hexa-hidratado e nitrato de alumínio nona-hidratado em $70 \mathrm{~mL}$ de água isenta de $\mathrm{CO}_{2}$, denominada solução "A". Em seguida preparou-se $150 \mathrm{~mL}$ de uma solução de hidróxido de sódio 2,0 mols L ${ }^{-1}$, denominada solução "B". A solução "A" foi adicionada lentamente à solução "B" sob agitação vigorosa, utilizando-se um funil de separação de haste prolongada. A temperatura de precipitação foi de $45{ }^{\circ} \mathrm{C}$. A síntese foi conduzida em atmosfera de nitrogênio e a fração sólida obtida foi lavada com água e seca a $70^{\circ} \mathrm{C}$ até massa constante $[17,21]$.

Os HDL e o estearato de zinco comercial (EZ) foram analisados, antes e após o uso como catalisadores, por espectroscopia vibracional na região do infravermelho com transformada de Fourier (IVTF) em um aparelho Bomem Michelson MB1000. As pastilhas de brometo de potássio foram preparadas após a mistura de $1 \%$ da amostra de teste em $\mathrm{KBr}$ seco e prensagem a 8 ton. As análises foram realizadas no modo de transmissão, na faixa de 4000 a $400 \mathrm{~cm}^{-1}$, com resolução de $2 \mathrm{~cm}^{-1}$ e aquisição de 16 varreduras. A análise dos materiais lamelares, antes e após o uso como catalisadores, por difração de raios X (DRX) foi conduzida em um aparelho Shimadzu DRX-6000 com radiação CuK $\alpha(\alpha=0,15418 \mathrm{~nm})$ operando a $40 \mathrm{kV}$ e $30 \mathrm{~mA}$. A velocidade de varredura foi de $1^{\circ} \mathrm{C} \mathrm{min}^{-1}$ de 3 a $60^{\circ} \mathrm{em} 2 \theta$. As distâncias interplanares foram obtidas utilizando-se a Lei de Bragg.

As reações de interesterificação do óleo de soja com acetato de metila foram conduzidas em um reator pressurizado de $100 \mathrm{~mL}$ de capacidade dotado de agitação mecânica, modelo miniclave drive fabricado pela Büchiglass. A pressão dentro do vaso de reação correspondeu à pressão de vapor do componente mais volátil presente no meio. Em todos os experimentos, a rotação do motor foi fixada em $600 \mathrm{rpm}$ (rotações por minuto). As reações foram conduzidas com $5 \% \mathrm{e}$ $15 \%$ de catalisador $\left(\mathrm{m} \mathrm{m}^{-1}\right)$, medido em relação à massa de óleo de soja utilizada na reação, e com razão molar acetato de metila: óleo de soja de 24:1 e 48:1. As reações foram conduzidas com intervalos de tempo de $1 \mathrm{a}$ 10h. Após alguns ensaios preliminares optou-se por fixar a temperatura de reação para todos os experimentos em $175^{\circ} \mathrm{C}$.

A composição química em ácidos graxos do óleo de palma e do EZ foram determinadas de acordo com o método desenvolvido por Hartman e Lago adaptado para microescala [22-24]. Em um procedimento típico, cerca de 0,2 g de amostra foram transferidas para um tubo de ensaio e saponificadas com 3,0 mL de uma solução $0,5 \mathrm{~mol} \mathrm{~L}^{-1}$ de hidróxido de sódio em metanol. Os tubos de ensaio foram então vedados e mantidos em banho-maria a $90^{\circ} \mathrm{C}$ por $10 \mathrm{~min}$. Em seguida foram adicionados $9,0 \mathrm{~mL}$ da solução esterificante, preparada previamente mediante a dissolução de $2 \mathrm{~g}$ de cloreto de amônio e $3,0 \mathrm{~mL}$ de ácido sulfúrico em $60 \mathrm{~mL}$ de metanol. $\mathrm{O}$ meio de reação foi mantido a $90^{\circ} \mathrm{C}$ por $10 \mathrm{~min}$. Terminada a reação, o sistema foi resfriado a temperatura ambiente, quando foi adicionado água destilada. A suspensão foi transferida para um funil de decantação, com adição de heptano. O sistema foi agitado vigorosamente e depois mantido em repouso para a separação de fases. A fase heptânica foi coletada e a fase aquosa extraída novamente com heptano. Os extratos heptânicos foram reunidos e lavados com água destilada até pH neutro. A fase orgânica foi seca com sulfato de sódio anidro e, em seguida, analisada por cromatografia em fase gasosa (CG).

A análise dos ésteres metílicos de ácidos graxos do óleo de soja e do EZ obtidos após o processamento utilizando-se o método de Hartman e Lago, conforme supracitado, bem como a análise do material graxo obtido após as reações de interesterificação, foram conduzidas utilizando-se de um cromatógrafo Shimadzu $u^{\circledR}$ GC-7AG com detector de ionização de chama. A separação dos componentes foi realizada em uma coluna capilar Zebron ${ }^{\circledR}$ ZB-WAX (30 m x 0,25 mm de diâmetro interno e filme de $0,25 \mu \mathrm{m})$. O gás de arraste utilizado foi o $\mathrm{H}_{2}$ em um fluxo de $1 \mathrm{~mL} \mathrm{~min}^{-1}$, enquanto que o volume de injeção foi de $1 \mu \mathrm{L}$ em razão de split de 1:20. As temperaturas do detector e do injetor foram ajustadas em $250^{\circ} \mathrm{C}$, com uma programação de aquecimento de $150^{\circ} \mathrm{C}$ até $240^{\circ} \mathrm{C}$ a uma taxa de $16^{\circ} \mathrm{C} \mathrm{min}^{-1}$, permanecendo a $250^{\circ} \mathrm{C}$ até a eluição total dos componentes. A identificação de cada composto foi realizada por comparação dos tempos de retenção de padrões cromatográficos de ésteres metílicos na faixa de oito a vinte e quatro átomos de carbonos. A quantificação de cada um dos componentes foi realizada pela adição de um padrão interno de heptadecanoato de metila.

A possível lixiviação do catalisador para o meio de reação foi avaliada submetendo-se as amostras de maior conversão à análise de metais por espectrometria de emissão ótica com fonte de plasma acoplado indutivamente (ICP OES). Em 
um procedimento típico, $4 \mathrm{~g}$ amostra foram dissolvidas em $2 \mathrm{~mL}$ de $\mathrm{H}_{2} \mathrm{O}_{2}$ à $30 \%$ e $10 \mathrm{~mL}$ de $\mathrm{HCl}$ ultrapuro (36 \%, v/v). Esta mistura foi aquecida a $90^{\circ} \mathrm{C}$ em um béquer de vidro Pirex ${ }^{\circledR}$, previamente limpo em solução de $\mathrm{HNO}_{3} 2 \%$ por $24 \mathrm{~h}$ e exaustivamente lavado com $\mathrm{H}_{2} \mathrm{O}$ ultrapura. $\mathrm{O}$ meio foi então agitado por $30 \mathrm{~min}$, com posterior resfriamento até a temperatura ambiente e centrifugação a $3.500 \mathrm{rpm}$ por $10 \mathrm{~min}$ para induzir a separação de fases. A fase ácida foi coletada e a camada orgânica submetida a uma nova extração com $8 \mathrm{~mL} \mathrm{de} \mathrm{H}_{2} \mathrm{O}$ a $90^{\circ} \mathrm{C}$ e agitação por $10 \mathrm{~min}$. As amostras foram então levadas a um balão volumétrico de $250 \mathrm{~mL}$, que foi aferido com água ultrapura. Um branco foi realizado seguindo o mesmo procedimento e utilizando os mesmos reagentes, porém, na ausência de amostra. As análises foram realizadas em um espectrofotômetro de emissão ótica, modelo iCAP 6500 Thermo Fisher Scientific ${ }^{\circledR}$. O equipamento possui um detector de estado sólido (CID), que permite a escolha contínua de comprimentos de onda na faixa de 166 a $847 \mathrm{~nm}$ e uma rede policromadora Echelle. A introdução das amostras foi realizada com nebulizador concêntrico acoplado a uma câmara ciclônica. As curvas analíticas para quantificação dos metais foram construídas com intervalos lineares de $1,000 \mu \mathrm{g} \mathrm{L}^{-1}$ a $1,000 \mathrm{mg} \mathrm{L}^{-1}$, limite de quantificação de $1,000 \mu \mathrm{g} \mathrm{L}^{-1}$ e padronização interna com ítrio na concentração de $0,100 \mathrm{mg} \mathrm{L}^{-1}$ [25].

\section{RESULTADOS}

O índice de saponificação e o índice de acidez determinados para o óleo de soja refinado foram de 206,8 $\mathrm{mg} \mathrm{KOH} \mathrm{g}^{-1}$ de amostra e $0,8 \mathrm{mg} \mathrm{KOH} \mathrm{g}^{-1}$, respectivamente. A composição química em ácidos graxos para o óleo de soja refinado e para o EZ são apresentados na Tabela 1 .

Tabela 1: Parâmetros físicos e químicos determinados para o óleo de soja e para o estearato de zinco comercial (EZ).

\begin{tabular}{c|c|c|c}
\hline $\mathbf{C m}_{\mathbf{n}} \mathbf{1}^{\mathbf{1}}$ & Ácido graxo & Óleo de soja (\%) & EZ (\%) \\
\hline C $14: 1$ & Miristoleico & - & 2,3 \\
\hline C $16: 0$ & Palmítico & 3,9 & 33,8 \\
\hline C $18: 0$ & Esteárico & 23,7 & 59,7 \\
\hline C $18: 1$ & Oleico & 53,6 & - \\
\hline C $18: 2$ & Linoléico & 6,2 & 1,6 \\
\hline C $18: 3$ & Linolênico & 1,7 & 0,4 \\
\hline Outros $^{2}$ & - & 1,3 \\
\hline
\end{tabular}

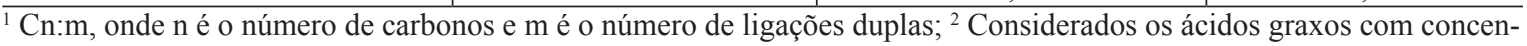
tração inferior a $0,5 \%$.

A Figura 4 mostra o DRX e o IVTF do HDL e do EZ antes e após o uso como catalisadores na interesterificação do óleo de soja refinado com acetato de metila.
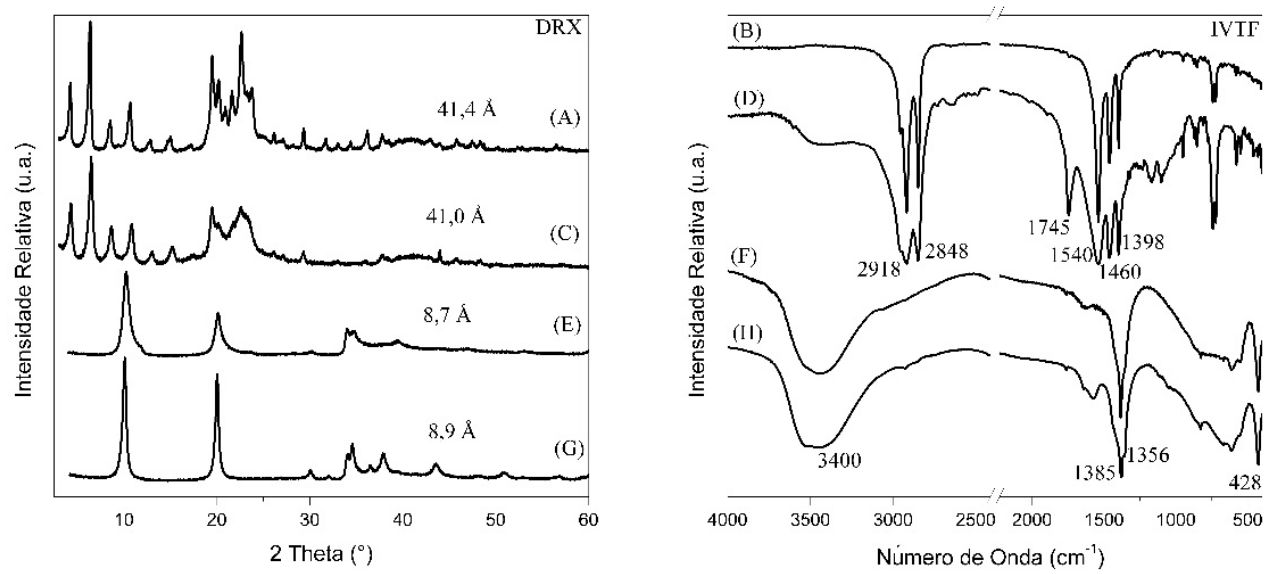

Figura 4: Difratogramas de raios X (DRX) e espectros vibracionais de infravermelho com transformada de Fourier (IVTF) dos materiais lamelares antes e após o uso como catalisadores: (A,B) EZ antes, (C,D) EZ após, (E,F) HDL antes e (G,H) HDL após. 
A Tabela 2 mostra os resultados obtidos nas reações de interesterificação do óleo de soja com acetato de metila utilizando os catalisadores HDL e EZ. A triacetina obtida como coproduto foi quantificada apenas para o experimento de maior conversão em ésteres metílicos (experimento 8, Tabela 2), sendo que o valor obtido foi de 7,7 $\pm 2,3 \%\left(\mathrm{~m} \mathrm{~m}^{-1}\right)$. As amostras dos experimentos 7 (utilizando o EZ) e 8 (utilizando o HDL) (Tabela 2) foram obtidas utilizando-se $15 \%$ de catalisador. Estas amostras foram submetidas a análise química afim de verificar a possível lixiviação de íons zinco para o meio de reação. A quantidade de íons zinco encontrada nas amostras 7 e 8 foram, respectivamente, $19,5 \mathrm{mg} \mathrm{Kg}^{-1}$ de amostra e 79,1 $\mathrm{mg} \mathrm{Kg}{ }^{-1}$ de amostra.

Tabela 2: Interesterificação do óleo de soja com acetato de metila

\begin{tabular}{c|c|c|c|c|c}
\hline \multirow{2}{*}{ Experimento } & \multirow{2}{*}{ Tempo (h) } & \multicolumn{2}{|c|}{ \% Catalisador } & \multirow{2}{*}{ RM $^{3}$} & \multirow{2}{*}{ \% Ésteres metílicos } \\
\cline { 3 - 5 } & 1 & $\mathbf{H D L}^{\mathbf{1}}$ & $\mathbf{E Z}^{2}$ & & \\
\hline 1 & 1 & - & 15 & $48: 1$ & $4,5 \pm 0,7$ \\
\hline 2 & 2 & 15 & - & $48: 1$ & $17,6 \pm 2,1$ \\
\hline 3 & 2 & - & 15 & $48: 1$ & $9,3 \pm 2,7$ \\
\hline 4 & 3 & 15 & - & $48: 1$ & $30,5 \pm 2,5$ \\
\hline 5 & 3 & - & 15 & $48: 1$ & $12,3 \pm 2,1$ \\
\hline 6 & 10 & 15 & - & $48: 1$ & $28,4 \pm 3,3$ \\
\hline 7 & 10 & - & 15 & $48: 1$ & $64,5 \pm 0,8$ \\
\hline 8 & 10 & 15 & - & $48: 1$ & $85,3 \pm 2,9$ \\
\hline 9 & 10 & - & 5 & $24: 1$ & $50,8 \pm 4,2$ \\
\hline 10 & 10 & 5 & - & $24: 1$ & $82,9 \pm 1,0$ \\
\hline $11^{4}$ & - & - & $48: 1$ & $5,7 \pm 0,2$ \\
\hline
\end{tabular}

Todas as reações foram conduzidas a $175^{\circ} \mathrm{C}$, com agitação mecânica de $600 \mathrm{rpm}$ (rotações por minuto). ${ }^{1}$ Hidróxido duplo lamelar (HDL) $\mathrm{Zn}_{2} \mathrm{Al} / \mathrm{NO}_{3} ;{ }^{2}$ Estearato de zinco comercial (EZ); ${ }^{3}$ Razão molar acetato de metila:óleo de soja; ${ }^{4}$ Experimento realizado sem adição de catalisador (branco).

\section{DISCUSSÃO}

O índice de saponificação e o índice de acidez determinados para o óleo de soja estão de acordo com os valores esperados para essa matéria-prima [1]. A determinação do índice de saponificação neste trabalho foi importante porque a quantidade de material graxo presente no óleo de soja que teoricamente poderia ser transformada em ésteres metílicos de ácidos graxos pode ser quantificada utilizando-se o índice de saponificação. Este índice também foi utilizado na determinação da massa molar média do óleo de soja, parâmetro importante para se estabelecer as relações estequiométrica para as reações, cujo valor obtido foi $813 \mathrm{~g} \mathrm{~mol}^{-1}$. Os ácidos graxos presentes em maior quantidade no óleo de soja refinado corresponderam ao linoleico $(56,6 \%)$, oleico $(23,7 \%)$ e palmítico $(10,8 \%)$. Já os principais ânions carboxilato coordenados ao cátion zinco no EZ são as bases conjugadas dos ácidos esteárico $(59,7 \%)$ e palmítico (33,8\%) (Tabela 1).

O perfil de difração do EZ é típico de sólidos lamelares (Figura 4). O espaçamento basal, determinado de acordo com a Lei de Bragg, correspondeu a 41,4 $\AA$, um valor intermediário entre o do palmitato (38,1 $\AA$ ) e o estearato (42,6 $\AA$ ) de zinco. Este valor de espaçamento basal do EZ é característico para este composto comercial, cuja composição em ácidos graxos é centrada nos ácidos palmítico e esteárico (Tabela 1). A análise por IVTF do EZ (Figura 4) evidenciou bandas em 2848 e $2918 \mathrm{~cm}^{-1}$, correspondentes às deformações axiais simétrica e assimétrica de $\mathrm{C}-\mathrm{H}$ em grupos $-\mathrm{CH}_{2}-\mathrm{e}-\mathrm{CH}_{3}$, e em 1398 e $1460 \mathrm{~cm}^{-1}$, relativas às deformações angulares destas mesmas ligações $\mathrm{C}-\mathrm{H}$. Em $1540 \mathrm{~cm}^{-1}$, observa-se uma banda referente à deformação axial assimétrica de O-C-O (ânions carboxilatos). O espaçamento basal determinado para o HDL foi $8,7 \AA$, sendo coerente com a presença de íons nitrato no espaço interlamelar (Figura 4). No espectro de IVTF do HDL é observada uma banda larga na região de $3400 \mathrm{~cm}^{-1}$, atribuída à deformação axial de grupos $\mathrm{O}-\mathrm{H}$ associados à estrutura do material lamelar e moléculas de água de hidratação dos íons intercalados. As bandas em números de onda inferiores a $500 \mathrm{~cm}^{-1}$ correspondem aos modos de vibração de ligações metal-oxigênio, enquanto que as bandas em 1385 a $1356 \mathrm{~cm}^{-1}$ correspondem às deformações axiais de íons nitrato (Figura 4). A análise dos sólidos antes e após o uso como catalisadores por IVTF e DRX não revelaram alterações estruturais importantes nos matérias lamelares, sugerindo que potencialmente 
estes materiais são passíveis de reuso como catalisadores nas reações de interesterificação do óleo de soja refinado com o acetato de metila. Porém, são necessários novos experimentos para confirmar essa hipótese [16-17, 19-20, 26].

A maioria dos experimentos de interesterificação do óleo de soja com acetato de metila foram conduzidos com razão molar (RM) acetato de metila: óleo de soja de 48:1 e 15\% de catalisador (Tabela 2). Alguns experimentos foram conduzidos com RM 24:1 e 5\% de catalisador. Estequiometricamente, três mols de acetato de metila reagem com um mol de triacilglicerídeo para formar três mols de ésteres metílicos de graxos e um mol de triacetina. Porém, optou-se pelo uso de reagente em excesso para deslocar o equilíbrio químico e tentar maximizar a conversão em ésteres metílicos de graxos e triacetina. Essa estratégia foi baseada no trabalho de Cordeiro e colaboradores, que utilizam o hidroxinitrado de zinco (um sólido lamelar) como catalisador na metanólise do óleo de palma [15]. Convém enfatizar que ambas as reações, transesterificação e interesterificação, são reações governadas pelo equilíbrio químico. Observa-se que as conversões em ésteres metílicos foram baixas para ambos os sistemas catalíticos quando as reações foram conduzidas por $1 \mathrm{~h}$. Porém, após $10 \mathrm{~h}$ de reação foram obtidas conversões em ésteres metílicos da ordem de 64 e 85\% com o uso de EZ e de HDL, respectivamente. A análise dos resultados obtidos nos experimentos 7 ao 8 , ambos conduzidos sob as mesmas condições de reação, revelou que o desempenho catalítico do HDL é superior ao do EZ para todas as condições testadas. Esta mesma conclusão é obtida analisando os experimentos 1-2; 3-4 e 5-6 (Tabela 2).

Foram realizados ainda dois experimentos com menor razão molar e menor quantidade percentual de catalisador. Considerando o erro experimental (Tabela 2), a conversão em ésteres metílicos diminuiu ligeiramente quando o EZ é utilizado como catalisador (experimentos 7 e 9). Porém, os experimentos 8 e 10 sugerem que, dentro do erro experimental, a conversão em ésteres metílicos não é alterada quando se utiliza 5\% de HDL e RM de 24:1, ao invés de 15\% de HDL e RM de 48:1.

Há vantagens evidentes entre o processo alternativo de interesterificação de óleo de soja com acetato de metila, catalisado por sólidos lamelares (HDL e EZ), sobre o processo tradicional de produção de biodiesel, que corresponde a transesterificação em meio alcalino homogêneo. O processo alternativo é conduzido em meio heterogêneo, potencialmente levando à formação de produtos com maior grau de pureza e com a possibilidade de reutilização do catalisador. A glicerina obtida na interesterificação já é quimicamente modificada, na forma de triacetina, evitando assim a necessidade de processos complementares para o seu beneficiamento. Para cada 100 ton de óleo de soja submetido ao processo de interesterificação, cerca de 10 ton de triacetina poderiam ser obtidos. Como os experimentos listados na Tabela 2 foram conduzidos em escala laboratorial, optou-se por quantificar apenas a triacetina obtida para o experimento de maior conversão em ésteres metílicos (experimento 8, Tabela 2). O valor encontrado foi de 7,7 $\pm 2,3 \%\left(\mathrm{~m} \mathrm{~m}^{-1}\right)$ de triacetina para um experimento em que a conversão em ésteres metílicos de ácidos graxos foi de 85,3 $\pm 2,9$. É importante enfatizar que para cada $100 \mathrm{~g}$ de triacilglicerídeo processados, cerca de $10 \mathrm{~g}$ de glicerol seriam convertidos em triacetina; se todo o triacilglicerídeo fosse transformado em ésteres metílicos de ácidos graxos.

Afim de confirmar que a conversão em ésteres metílicos, observada nos resultados apresentados na Tabela 2, se deve à atividade catalítica dos sólidos lamelares e não apenas à conversão térmica, o experimento 11 foi conduzido sem a adição de catalisador (experimento em branco) na condição mais enérgica dentre as testadas (RM de 48:1 e $10 \mathrm{~h}$ de reação). A conversão obtida no experimento em branco foi baixa ( $\sim 5 \%)$, confirmando assim, a atividade catalítica do HDL e do EZ em reações de interesterificação do óleo de soja com acetato de metila.

As amostras dos experimentos 7 (utilizando o EZ) e 8 (utilizando o HDL) (Tabela 2) foram obtidas utilizando-se 15 $\%$ de catalisador. Estas amostras foram submetidas a análise química afim de verificar a possível lixiviação de íons zinco para o meio de reação. A quantidade de íons zinco encontrada na amostra 7 (19,5 mg Kg${ }^{-1}$ de amostra) correspondeu a apenas $\sim 0,3 \%$ da quantidade de zinco presente no catalisador EZ adicionado no início do experimento $\left(5.730 \mathrm{mg} \mathrm{Kg}^{-1} \mathrm{de}\right.$ amostra). A análise da amostra obtida no experimento 8 revelou a presença de 79,1 mg de zinco por quilograma de amostra, e como foram adicionados neste experimento $29.430 \mathrm{mg}$ de zinco oriundos do HDL, confirmou-se que apenas $\sim 0,3 \%$ de íons zinco foi lixiviado para o meio de reação. Entretanto, é provável também que os íons zinco detectados na fase líquida não sejam oriundos da solubilização dos materiais lamelares, mas de materiais sólidos nanoparticulados não removidos pelos processos tradicionais de separação.

\section{CONCLUSÕES}

Neste trabalho, o estearato de zinco comercial (EZ) e o hidróxido duplo lamelar (HDL) $\mathrm{Zn}_{2} \mathrm{Al} / \mathrm{NO}_{3}$ foram utilizados como catalisadores para a interesterificação do óleo de soja refinado com o acetato de metila. Esse processo possibilitou a obtenção da glicerina já quimicamente modificada, na forma de triacetina, evitando assim processos posteriores de beneficiamento do coproduto. Todas as reações foram realizadas a $175^{\circ} \mathrm{C}$, com razão molar (RM) acetato de metila: óleo de soja de 24:1 e 48:1 e quantidades percentuais de catalisadores de 5 e $15 \%\left(\mathrm{~m} \mathrm{~m}^{-1}\right)$. As reações foram conduzidas em intervalos de tempo de 1 a 10 h. Para ambos os catalisadores, foi observado um aumento na conversão em ésteres metílicos com o aumento do tempo de residência dos reagentes e catalisador no reator. Quando a reação foi conduzida com 5\% de catalisador e RM 
24:1, a conversão em ésteres metílicos obtida foi de 50,8 $\pm 4,2$ e $82,9 \pm 1,0 \%\left(\mathrm{~m} \mathrm{~m}^{-1}\right)$, utilizando como catalisadores o EZ e o HDL, respectivamente. Para reações conduzidas com 15\% de catalisador e RM 48:1, mantendo-se as outras condições, as conversões obtidas foram $64,5 \pm 0,8$ e $85,3 \pm 2,9 \%\left(\mathrm{~m} \mathrm{~m}^{-1}\right)$, para EZ e HDL, respectivamente. Ou seja, houve alguma variação na conversão obtida com o EZ, com o aumento da porcentagem de catalisador e RM, porém, a conversão obtida com o HDL manteve-se constante, considerando o erro experimental. Virtualmente pode-se dizer que não houve lixiviação de íons zinco para o meio de reação.

\section{AGRADECIMENTOS}

O presente trabalho foi realizado com apoio da Coordenação de Aperfeiçoamento de Pessoal de Nível Superior - Brasil (CAPES) - Código de Financiamento 001, Conselho Nacional de Desenvolvimento Científico e Tecnológico (CNPq) (proc.: 303846/2014-3 e 400117/2016-9) e Financiadora de Estudos e Projetos (Finep).

\section{BIBLIOGRAFIA}

[1] RAMOS, L.P., KOTHE, V., CÉSAR-OLIVEIRA, M.A.F., et al. Biodiesel: matérias-primas, tecnologias de produção e propriedades combustíveis. Revista Virtual de Química; v. 9, p. 317-369, 2017.

[2] MA, F., HANNA, M.A, Biodiesel production: a review. Bioresource Technology; v. 70, pp. 1-15, 1999.

[3] SCHUCHARDT, U., SERCHELI, R., VARGAS, R.M., Transesterification of vegetable oils: a review. Journal of the Brazilian Chemical Society; v. 9, pp. 199-210, 1998.

[4] KUCEK, K.T., CÉSAR-OLIVEIRA, M.A.F., WILHELM, H., et al. Ethanolysis of Refined Soybean Oil Assisted by Sodium and Potassium Hydroxides. Journal of the American Oil Chemists' Society; v. 84, pp. 385-392, 2007.

[5] COSTA NETO, P.R., ROSSI, L.F.S., ZAGONEL, G.F., et al. 1999. Produção de biocombustível alternativo ao óleo diesel através da transesterificação de óleo de soja usado em frituras. Química Nova; v.23 , pp.531-537.

[6] CORDEIRO, C.S., SILVA, F.R., WYPYCH, F., et al. 2011. Catalisadores heterogêneos para a produção de monoésteres graxos (biodiesel). Química Nova; v. 34, pp. 477-486.

[7] MARDHIAH, H.H., ONG, H.C., MASJUKI, H.H., et al. 2017. A review on latest developments and future prospects of heterogeneous catalyst in biodiesel production from non-edible oils. Renewable and Sustainable Energy Reviews; v. 67, pp. 1225-1236.

[8] AMBAT, I., SRIVASTAVA, V., SILLANPÄÄ, M. Recent advancement in biodiesel production methodologies using various feedstock: A review. Renewable and Sustainable Energy Reviews; v. 90, pp. 356-369.

[9] CASAS, A., RAMOS, M.J., PÉREZ, Á., 2011. New trends in biodiesel production: Chemical interesterification of sunflower oil with methyl acetate. Biomass and Bioenergy; v. 35, pp. 1702-1709.

[10] XU, Y., DU, W., LIU, D., 2005. Study on the kinetics of enzymatic interesterification of triglycerides for biodiesel production with methyl acetate as the acyl acceptor. Journal of Molecular Catalysis B: Enzymatic; v. 32, pp. 241-245.

[11] CASAS, A., RAMOS, M.J., PÉREZ, Á., 2013. Methanol-enhanced chemical interesterification of sunflower oil with methyl acetate. Fuel; v. 106, pp. 869-872.

[12] BONET, J., COSTA, J., SIRE, R., et al. 2009. Revalorization of glycerol: Comestible oil from biodiesel synthesis. Food and Bioproducts Processing; v. 87, pp. 171-178.

[13] CASAS, A., RUIZ, J.R., RAMOS, M.J., PÉREZ, Á., 2010. Effects of Triacetin on Biodiesel Quality. Energy Fuels; v. 24, pp. 4481-4489.

[14] MOTA, C.J.A., SILVA, C.X.A., GONÇALVES, V.L.C., 2009. Gliceroquímica: novos produtos e processos a partir da glicerina de produção de biodiesel. Química Nova; v. 32, pp. 639-648.

[15] CORDEIRO, C.S., ARIZAGA, G.G.C., RAMOS, L.P., et al. 2008. A new zinc hydroxide nitrate heterogeneous catalyst for the esterification of free fatty acids and the transesterification of vegetable oils. Catalysis Communications; v. 9 , pp. 2140-2143.

[16] LISBOA, F.S.; GARDOLINSKI, J.E.C., CORDEIRO, C.S., et al. 2012. Layered metal laurates as active catalysts in the methyl/ethyl esterification reactions of lauric acid. Journal of the Brazilian Chemical Society; v. 23, pp. 46-56.

[17] CORDEIRO, C.S., SILVA, F.R., MARANGONI, R., et al. 2012. LDHs Instability in Esterification Reactions and Their Conversion to Catalytically Active Layered Carboxylates. Catalysis Letters; v. 142, pp. 763-770. 
[18] RAMOS, L.P., SILVA, F.R., MANGRICH, A.S., et al. 2011. Tecnologias de Produção de Biodiesel. Revista Virtual de Química; v. 3, pp. 385-405.

[19] RAMOS, L.P., BRUGNAGO, R.J., SILVA, F.R., et al. 2015. Esterificação e transesterificação simultâneas de óleos ácidos utilizando carboxilatos lamelares de zinco como catalisadores bifuncionais. Química Nova; v. 38, pp. 46-54.

[20] ESCORSIM, A.M., HAMERSKI, F., RAMOS, L.P., et al. 2019. Multifunctionality of zinc carboxylate to produce acylglycerols, free fatty acids and fatty acids methyl esters. Fuel; v. 244, pp. 569-579.

[21] YANG, Q.Z., YANG, J., ZHANG, C.K., 2006. Synthesis and properties of cordycepin intercalates of Mg-Al-nitrate layered double hydroxides. International Journal of Pharmaceutics; v. 326, pp. 148-152.

[22] HARTMAN, L., LAGO, R.C.A., 1973. Rapid preparation of fatty acids methyl esters. Laboratory practice; v. 22, pp. 475-476.

[23] MENEZES, R.S., LELES, M.I.G., SOARES, A.T., et al. 2013. Avaliação da potencialidade de microalgas dulcícolas como fonte de matéria-prima graxa para a produção de biodiesel. Química Nova; v. 36, pp. 10-15.

[24] BAUMGARDT, F.J.L., ZANDONÁ FILHO, A., BRANDALIZE, M.V., et al. 2016. Lipid content and fatty acid profile of Nannochloropsis oculata before and after extraction with conventional solvents and/or compressed fluids. The Journal of Supercritical Fluids; v. 108, pp. 89-95.

[25] DUGO, G., PERA, L.L., TURCO, V.L., et al. 2003. Determination of Selenium in Nuts by Cathodic Stripping Potentiometry (CSP). Journal of Agricultural and Food Chemistry; v. 51, pp. 3722-3725.

[26] TAYLOR, R.A., ELLIS, H.A., 2007. Room temperature molecular and lattice structures of a homolgousseries of anhydrous zinc(II)n-alkanoate. Spectrochimica Acta Part A; v. 68, pp. 99-107.

\section{ORCID}

Aligia Arrubia Useda

Fernando Wypych

Claudiney Soares Cordeiro https://orcid.org/0000-0002-6918-8326

https://orcid.org/0000-0002-3498-8323

https://orcid.org/0000-0002-3446-4386 